\title{
Thermostability differences of allozyme loci in Mytilus edulis, M. galloprovincialis and hybrid mussels
}

\author{
J. P. A. Gardner, D. O. F. Skibinski \\ Biomedical and Physiological Research Group, School of Biological Sciences, University College of Swansea, Singleton Park, \\ Swansea SA2 8PP, United Kingdom
}

\begin{abstract}
A comparison of allozyme thermostability was made between Mytilus edulis and $M$. galloprovincialis populations, and between $M$. edulis-like and $M$. galloprovincialis-like mussels of a hybrid population, all from SW Britain. In all 3 populations, alleles at 3 polymorphic allozyme loci (Odh, Pgi and Pgm) of the 8 mono- and polymorphic allozyme loci examined were found to exhibit thermosensitivity. For all 3 populations following heat treatment, there was a mean increase of $63 \%$ in the total number of detectable alleles at these loci. Two analyses provided evidence of a significantly greater frequency of heat-sensitive alleles in the $M$. edulis genome, whilst one analysis provided evidence of a significantly greater frequency in the M. galloprovincialis genome. However, the majority of allele-by-allele and locus-by-locus comparisons revealed no significant difference in the frequencies of heat-sensitive alleles found in $M$. edulis and $M$. galloprovincialis. Nei's genetic distance (D) computed from allele frequencies at a locus, and at all 3 loci together, showed similar values before and after heat treatment. Overall the results suggest that there is no difference in the frequency of heatsensitive alleles in $M$. edulis (a cold-water form) and in $M$. galloprovincialis (a warm-water form). Our results contrast with previous studies of heat-sensitivity in marine organisms, all of which have reported significant differences in heat-sensitive allele frequencies in intra-specific comparisons between geographically distinct regions with differing temperature regimes.
\end{abstract}

\section{INTRODUCTION}

Electrophoresis is a very widely used technique in genetic analysis, but it is estimated to detect only $1 / 3$ of the protein sequence variation present (e.g. Bonhomme \& Selander 1978, Trippa et al. 1978). Heat denaturing techniques have revealed additional genetic variation within single and multiple loci of marine algae (Okumura \& Fujino 1986), Drosophila (Bernstein et al. 1973, Singh et al. 1974, 1975, Milkman 1976), marine molluscs (Gosling 1979, Wilkins et al. 1980, Okumura et al. 1981), mice (Bonhomme \& Selander 1978), and in human haemoglobin (Bernstein et al. 1980).

Within wild populations of marine organisms such as algae (Okumura \& Fujino 1986), mussels (Gosling 1979) and abalones (Wilkins et al. 1980, Okumura et al. 1981), allozyme thermosensitivity has been related to environmental temperature variation. Consequently allozyme thermostability is thought to be of adaptive significance. Comparisons of intra-specific allozymic thermostability from geographically distinct regions have typically shown a greater frequency of thermosensitive alleles in populations from colder locations. That is, thermosensitive alleles are presumed to be selected against in warmer regions.

The Mediterranean mussel Mytilus galloprovincialis reaches its northem-most limits of distribution on the shores of Britain and Ireland (Seed 1971, 1976, Gosling 1984). In Britain, M. galloprovincialis is found mainly in SW England (Skibinski et al. 1983) where it occurs sympatrically and hybridizes with $M$. edulis (Ahmad \& Beardmore 1976, Skibinski 1983, Gardner \& Skibinski $1988,1990)$. Within the zone of sympatry, on a localized scale, $M$. galloprovincialis is more abundant than $M$. edulis in both the high shore (Skibinski 1983, Gardner \& Skibinski 1988) and in more exposed locations (Gosling \& Wilkins 1981, Skibinski et al. 1983).

Hybrid Mytilus edulis/galloprovincialis populations exhibit length-dependent allele frequency variation with larger mussels having a greater frequency of alle- 
les which are at highest frequency in $M$. galloprovincialis (Skibinski 1983). The most likely explanation for the length-dependent allele frequencies of the hybrid populations is selective mortality of $M$. edulis mussels, as the 2 other hypotheses advanced by Skibinski (1983) as explanation, (1) historical change and (2) differential growth, can now be rejected (Gardner \& Skibinski 1988, Gardner 1989).

Water temperature in SW England rarely exceeds $20^{\circ} \mathrm{C}$ and usually reaches a maximum of 15 to $18^{\circ} \mathrm{C}$ (Seed 1971, Bayne \& Widdows 1978, Hawkins et al. 1985). This compares with a Mediterranean temperature maximum which regularly exceeds $25^{\circ} \mathrm{C}$ (Ceccherelli \& Barboni 1983) and which can reach up to $30^{\circ} \mathrm{C}$ (Biel 1944, Miller et al. 1970). Thus, temperaturedependent selection amongst constantly submerged mussels is likely to be greater in the Mediterranean than in SW England. However, the Mediterranean has a mean tidal range of only $0.3 \mathrm{~m}$ (Pugh 1987) such that the intertidal zone is limited in its extent. Most marine organisms in the Mediterranean remain immersed for the majority of their lifespan, whereas in SW England, as in many other regions, intertidal mussels can be emerged for as long as $6 \mathrm{~h}$ per tidal cycle. Because of their dark shell colouration and their position on exposed rocks, mussels can experience very high temperatures for long periods of time when emerged (Bayne et al. 1976). Consequently, mussels high in the intertidal zone of SW England can experience greater temperature-dependent selection for heat-stable alleles than mussels in the Mediterranean which are buffered by constant immersion. Thus, because of the evolutionary history and the apparent superior fitness of Mytilus galloprovincialis-like mussels compared with $M$. edulislike mussels in high shore locations in SW England (Gardner 1989), it might be predicted that there is a greater frequency of heat-sensitive alleles in the $M$. edulis genome than in the $M$. galloprovincialis genome.

In this paper we describe an investigation of the thermosensitivity of allozyme loci in Mytilus edulis, $M$. galloprovincialis and hybrid $M$. edulis/galloprovincialis populations. Based upon the possible adaptive value of allozyme thermostability, we test the null hypotheses: (1) that there is no difference in the frequency of allozyme thermosensitivity between $M$. edulis, $M$. galloprovincialis and hybrid populations, and (2) that within the hybrid population there is no difference in the frequency of allozyme thermosensitivity between M. edulis-like and M. galloprovincialis-like individuals. If differences in the frequencies of thermosensitivity exist between $M$. edulis and $M$. galloprovincialis which favour $M$. galloprovincialis-like individuals, i.e. M. edulis-like mussels are selected against, this may partially explain the characteristic length-dependent allele frequencies of these populations.

\section{MATERIALS AND METHODS}

Mussels were collected from 3 sites in mid-August 1988 as follows: a Mytilus galloprovincialis population from Bude, N. Cornwall; a hybrid $M$. edulis/galloprovincialis population from Croyde Bay, $N$ Devon (both sites in SW England); and a $M$. edulis population from Caswell Bay, S Wales. Water temperature in SW England rarely exceeds $20^{\circ} \mathrm{C}$ and usually reaches a maximum of 15 to $18^{\circ} \mathrm{C}$ in August, and falls to a minimum of 5 to $6^{\circ} \mathrm{C}$ in February (Seed 1971, Bayne \& Widdows 1978). The mean monthly minimum seawater temperature for the period 1854 to 1958 was $8^{\circ} \mathrm{C}$ in February, whereas the mean monthly maximum was $15^{\circ} \mathrm{C}$ in both August and September (Anon. 1975). At Ilfracombe, N Devon, the nearest Meteorological Station to Croyde, average monthly maximum air temperature for the period 1941 to 1970 was $24.2^{\circ} \mathrm{C}$ in July, and the average monthly minimum was $-1.3^{\circ} \mathrm{C}$ in January and February. For the same period, the absolute maximum air temperature was $30.0^{\circ} \mathrm{C}$ in June and August (years unknown) and the absolute minimum was $-6.7^{\circ} \mathrm{C}$ in February (year unknown) (Anon. 1976).

Fifty mussels each from Bude and Caswell, and 138 mussels from Croyde, were used for starch gel electrophoresis as described by Ahmad et al. (1977). The thermosensitivity of alleles at a total of 8 mono- and polymorphic loci was investigated. Four loci, esteraseD (EST-D; EC 3.1.1.1), leucine aminopeptidase (LAP; EC 3.4.1.1), lactate dehydrogenase (LDH; EC 1.1.1.27) and octopine dehydrogenase $\left(\mathrm{ODH}_{;} \mathrm{EC} 1.51 .11\right)$ were run on a tris-citric acid ( $\mathrm{pH}$ 6.9) buffered gel (Grant \& Cherry 1985). The remaining loci, aminopeptidase (AP; EC 3.4.1.3), phosphoglucose isomerase (PGI; EC 5.3.1.9), phosphoglucomutase (PGM; EC 2.7.5.1) and xanthine dehydrogenase $(\mathrm{XDH}$; EC 1.2.1.37) were run on a tris-maleate ( $\mathrm{pH}$ 7.4) buffered gel (Ahmad et al., 1977). The following staining methods were employed: that of Ahmad et al. (1977) for EST-D and LAP; Beaumont et al. (1980) for ODH; Skibinski et al. (1983) for $A P$ and PGI; Shaw \& Prasad (1970) for PGM and $X^{2} H_{i}$ and Harris \& Hopkinson (1977) for $\mathrm{LDH}_{\text {, but with }}$ sodium lactate substituted for calcium lactate.

The thermosensitivity of allozymes at each locus was determined by running the gel in the standard manner and then cutting it length-wise into 2 slices of equal thickness. Both slices were laid in plastic staining trays and then placed inside re-sealable plastic bags. One slice was used as the control, whilst the test slice was placed in a pre-heated water bath for a previously determined period. Both slices were then stained at the same time for the same allozyme locus to test for alleledependent heat-sensitivity differences. Of the 8 loci tested, 3 (Odh, Pgi, Pgm) showed heat-sensitive alleles and could be accurately scored after heating. Of the 
remaining loci, $A p, E s t-D, L d h$ and $X d h$ showed no apparent allele-specific heat-sensitivity, whereas Lap, if held at $55^{\circ} \mathrm{C}$ for $6 \mathrm{~min}$, showed some differential sensitivity but could not be accurately scored. Hence, we concentrated effort upon the Odh, Pgi and Pgm loci. The heat treatment involved the test slices being held at $55^{\circ} \mathrm{C}$ for 6,10 and $12 \mathrm{~min}$ for Odh, Pgi and Pgm respectively. The temperature and times were determined empirically. As in previous thermostability studies (Gosling 1978, Wilkins et al. 1980, Okumura et al. 1981, Fujino et al. 1984, Okumura \& Fujino 1986) a genotype was said to be heat-sensitive if there was no apparent activity after heating when compared with the control slice, otherwise the genotype was scored as heat-resistant. Thus, 2 types of homozygote were recognized: those in which the band was heat-resistant or heat-sensitive. Four types of heterozygotes were recognised: those in which both bands were heat-resistant or heat-sensitive, and those in which one or other of the bands was heat-sensitive. The disadvantage of this scoring system is that a homozygote with 2 alleles of equal electrophoretic mobility but of dissimilar thermosensitivity will be scored as being a homozygote for the thermostable allele. This results in an over-estimation of homozygote frequencies.

Est-D and Odh are amongst the most diagnostic loci for allele frequency differences between Mytilus edulis and M. galloprovincialis (Skibinski 1983, Gardner \& Skibinski 1988, 1990). The genotype of each mussel from the hybrid population was determined for these 2 loci to allow comparison of potential genotype-dependent differences in thermosensitivity at the 3 heat-sensitive loci.

Contingency tests using the method of Nass (1959) were used to compare the frequency of heat-sensitive and heat-resistant alleles between populations. Nass's test is particularly suitable for such an analysis because it allows for small observed and expected values. Nei's genetic distance ( $D$; Nei 1972) was used to measure genetic similarity before and after heat treatment.

\section{RESULTS}

All 3 populations exhibited heat-sensitive alleles at 3 of the 8 loci (Table 1). Heat-sensitive allele frequencies per locus varied considerably, both within and between sites. Overall frequencies at Bude, Caswell and Croyde for the Odh locus were $0.233,0.320$ and 0.290 , respectively; for the Pgi locus frequencies were $0.010,0.060$ and 0.043 , respectively, and for the Pgm locus 0.133 , 0.080 and 0.087 , respectively. The heat-sensitive $O d h^{10}$ allele had the greatest frequency of any heat-sensitive allele at all loci within all populations (Table 1). Overall, heat-sensitive allele frequencies were significantly
Table 1. Frequencies of heat-resistant ( $\mathrm{Hr}$ )and heat-sensitive (Hs) alleles at the Odh, Pgi and Pgm loci for the Bude, Caswell and Croyde populations of Mytilus edulis, $M$. galloprovincialis and their hybrid. $\mathrm{N}$ : no mussels

\begin{tabular}{|c|c|c|c|c|c|c|c|}
\hline \multirow[t]{2}{*}{ Locus } & \multirow[t]{2}{*}{ Allele } & \multicolumn{2}{|c|}{ Bude } & \multicolumn{2}{|c|}{ Caswell } & \multicolumn{2}{|c|}{ Croyde } \\
\hline & & $\mathrm{Hr}$ & Hs & $\mathrm{Hr}$ & $\mathrm{Hs}$ & $\mathrm{Hr}$ & Hs \\
\hline \multirow[t]{8}{*}{ Odh } & 6 & 0 & 0 & 0 & 0.01 & 0 & 0.01 \\
\hline & 8 & 0.51 & 0.05 & 0.04 & 0.01 & 0.20 & 0.02 \\
\hline & 9 & 0.01 & 0 & 0 & 0 & 0 & 0 \\
\hline & 10 & 0.08 & 0.10 & 0.62 & 0.30 & 0.46 & 0.20 \\
\hline & 11 & 0 & 0 & 0.01 & 0 & 0 & 0 \\
\hline & 12 & 0.18 & 0.07 & 0.01 & 0 & 0.05 & 0.06 \\
\hline & $\Sigma$ & 0.77 & 0.23 & 0.68 & 0.32 & 0.71 & 0.29 \\
\hline & $N$ & \multicolumn{2}{|c|}{42} & \multicolumn{2}{|c|}{50} & \multicolumn{2}{|c|}{138} \\
\hline \multirow[t]{10}{*}{$P g i$} & 4 & 0 & 0 & 0 & 0 & 0.01 & 0 \\
\hline & 5 & 0.01 & 0 & 0.01 & 0 & 0.01 & 0 \\
\hline & 6 & 0.14 & 0 & 0.07 & 0 & 0.03 & 0 \\
\hline & 7 & 0.44 & 0 & 0.24 & 0.01 & 0.33 & 0.01 \\
\hline & 8 & 0.24 & 0.01 & 0.04 & 0 & 0.11 & 0 \\
\hline & 10 & 0.14 & 0 & 0.57 & 0.02 & 0.47 & 0.02 \\
\hline & 11 & 0.02 & 0 & 0.01 & 0.03 & 0.00 & 0.01 \\
\hline & 12 & 0 & 0 & 0 & 0 & 0 & 0 \\
\hline & $\Sigma$ & 0.99 & 0.01 & 0.94 & 0.06 & 0.96 & 0.04 \\
\hline & $\mathrm{N}$ & \multicolumn{2}{|c|}{49} & \multicolumn{2}{|c|}{50} & \multicolumn{2}{|c|}{138} \\
\hline \multirow[t]{10}{*}{$P g m$} & 6 & 0.03 & 0.01 & 0.01 & 0.01 & 0 & 0 \\
\hline & 7 & 0 & 0 & 0 & 0 & 0 & 0 \\
\hline & 8 & 0.10 & 0.03 & 0.13 & 0.02 & 0.08 & 0.02 \\
\hline & 9 & 0 & 0 & 0 & 0 & 0 & 0 \\
\hline & 10 & 0.54 & 0.04 & 0.57 & 0.03 & 0.54 & 0.05 \\
\hline & 11 & 0 & 0 & 0.01 & 0.01 & 0 & 0 \\
\hline & 12 & 0.17 & 0.05 & 0.20 & 0.01 & 0.27 & 0.02 \\
\hline & 14 & 0.02 & 0 & 0 & 0 & 0 & 0 \\
\hline & $\Sigma$ & 0.87 & 0.13 & 0.92 & 0.08 & 0.91 & 0.09 \\
\hline & $\mathrm{N}$ & \multicolumn{2}{|c|}{49} & \multicolumn{2}{|c|}{50} & \multicolumn{2}{|c|}{138} \\
\hline
\end{tabular}

higher at the Pgi locus $\left(\chi^{2}=4.126, \mathrm{df}=1, \mathrm{p}<0.05\right)$ within the Mytilus edulis than within the M. galloprovincialis population. There was no significant overall difference in the frequency for the Odh and Pgm loci between the $M$. galloprovincialis and the $M$. edulis populations (for Odh: $\chi^{2}=1.518, \mathrm{df}=1, \mathrm{p}>0.05$; for Pgm: $\chi^{2}=1.497, \mathrm{df}=1, \mathrm{p}>0.05$ ). For all 3 loci, the hybrid population had intermediate heat-sensitive allele frequencies.

Allele-by-allele analysis of the relative frequency of occurrence of the heat-sensitive and heat-resistant forms at each locus indicated that the heat-sensitive $O d h^{10}$ allele (the Odh allele at greatest frequency in $M$. edulis, e.g. Skibinski 1983, Gardner \& Skibinski 1988) occurred at a relatively higher frequency in the $M$. galloprovincialis than in the $M$. edulis population $\left(\chi^{2}=\right.$ 7.209, df $=1, \mathrm{p}<0.01)$. The heat-resistant Pgm $^{12}$ allele occurred at a significantly higher frequency $\left(\chi^{2}=\right.$ 6.393, df $=2, \mathrm{p}<0.05$ ) in the hybrid than in the pooled $M$. galloprovincialis and $M$. edulis populations. There were no other alleles which showed significant differ- 
Table 2. Heat sensitivity variation for the Odh, Pgi and Pgm loci within and between populations of $M y t i l u s$ edulis and $M$. galloprovincialis

\begin{tabular}{|c|c|c|c|c|c|c|c|c|c|c|c|c|}
\hline & \multicolumn{3}{|c|}{ Bude } & \multicolumn{3}{|c|}{ Caswell } & \multicolumn{3}{|c|}{ Croyde } & \multicolumn{3}{|c|}{ All combined } \\
\hline & Odh & $P g i$ & Pgm & Odh & $P g i$ & $P g m$ & $O d h$ & $P g i$ & $P g m$ & Odh & $P g i$ & Pgm \\
\hline No. mussels per locus & 42 & 49 & 49 & 50 & 50 & 50 & 138 & 138 & 138 & 230 & 237 & 237 \\
\hline No. electrophoretic alleles & 4 & 6 & 5 & 5 & 6 & 5 & 5 & 8 & 8 & 6 & 8 & 8 \\
\hline No. heat-sensitive alleles & 3 & 1 & 4 & 3 & 3 & 5 & 4 & 4 & 4 & 4 & 5 & 6 \\
\hline Total no. detectable alleles & 7 & 7 & 9 & 8 & 9 & 10 & 9 & 12 & 12 & 10 & 13 & 12 \\
\hline Increase in no. of alleles & 1.8 & 1.2 & 1.8 & 1.6 & 1.5 & 2.0 & 1.8 & 1.5 & 1.5 & 1.7 & 1.4 & 1.8 \\
\hline
\end{tabular}

ences between populations in the relative frequency of heat-sensitive and heat-resistant forms.

The presence of heat-sensitive alleles increased the total number of detectable alleles at each locus in each population (Table 2). The Odh, Pgi and Pgm loci exhibited mean increases in the total number of detectable alleles per locus of 39,72 and $77 \%$ respectively. Increases in the total number of detectable alleles were very similar for all 3 populations, being 1.57, 1.70 and 1.60 times greater at Bude, Caswell and Croyde, respectively.

At Croyde, heat-sensitive allele frequencies at each of the 3 loci were partitioned according to each mussel's genotype at the 2 diagnostic loci Est-D and $O d h$ (Table 3). Hence, heat-sensitive allele frequencies at

Table 3. Frequencies of heat-sensitive alleles at the Odh, Pgi and Pgm loci, for the 9 dilocus genotypes of the hybrid Mytilus edulis/galloprovincialis Croyde population. $\mathrm{N}$ : no. individuals

\begin{tabular}{|c|c|c|c|c|c|}
\hline \multicolumn{2}{|c|}{ Genotype } & \multirow[t]{2}{*}{$N$} & \multirow[t]{2}{*}{ Odh } & \multirow[t]{2}{*}{$P g i$} & \multirow[t]{2}{*}{$P g m$} \\
\hline Est-D & $O d h$ & & & & \\
\hline$E / E$ & $E / E$ & 70 & 0.34 & 0.05 & 0.11 \\
\hline$E / E$ & $E / G$ & 10 & 0.40 & 0 & 0.45 \\
\hline$E / E$ & $G / G$ & 5 & 0.50 & 0.08 & 0 \\
\hline$E / G$ & $E / E$ & 2 & 0 & 0 & 0 \\
\hline$E / G$ & $E / G$ & 8 & 0.31 & 0 & 0 \\
\hline$E / G$ & $G / G$ & 9 & 0.22 & 0.06 & 0 \\
\hline$G / G$ & $E / E$ & 3 & 0 & 0 & 0 \\
\hline$G / G$ & $E / G$ & 12 & 0.17 & 0 & 0.08 \\
\hline \multirow[t]{2}{*}{$G / G$} & $G / G$ & 19 & 0.17 & 0 & 0.03 \\
\hline & & 138 & & & \\
\hline
\end{tabular}

each locus were estimated for the Mytilus edulis-like, and for the $M$. galloprovincialis-like genotypes. The $M$. edulis-like genotype ( $E / E E / E)$ had a higher heat-sensitive allele frequency at all 3 loci than the $M$. galloprovincialis-like genotype $(G / G G / G)$. The difference was significant for $\operatorname{Odh}\left(\chi^{2}=4.893, \mathrm{df}=1, \mathrm{p}<0.05\right)$, but not for $P_{g i}\left(\chi^{2}=2.910\right.$, df $\left.=1, p>0.05\right)$ nor for $P_{g m}$ $\left(x^{2}=1.264, \mathrm{df}=1, \mathrm{p}>0.05\right)$.

Nei's genetic distance (D) was used as a measure of genetic divergence at each of the 3 heat-sensitive loci and at the 3 loci combined, before and after heat treatment (Table 4). Because of the nature of the scoring of the synthetic $E$ and $G$ alleles for the Odh locus where $M$. edulis and $M$. galloprovincialis do not share a common allele (Skibinski 1983), the value of I before

Table 4. Values of Nei's genetic distance (D) with one standard error $\left(\mathrm{S}_{\mathrm{D}}\right)$ before and after heat treatment for the Bude (Mytilus galloprovincialis) versus the Caswell ( $M$. edulis) populations, and for the $M$. edulis-like versus the $M$. galloprovincialis-like mussels of the hybrid Croyde population

\begin{tabular}{|lcccc|} 
& \multicolumn{2}{c}{ Bude vs Caswell } & \multicolumn{2}{c}{ Croyde } \\
& $\mathrm{D}$ & $\mathrm{S}_{\mathrm{D}}$ & $\mathrm{D}$ & $\mathrm{S}_{\mathrm{D}}$ \\
\hline Odh before & 1.11 & 1.42 & - & - \\
Odh after & 1.32 & 1.66 & - & - \\
Pgi before & 0.49 & 0.80 & 0.56 & 0.87 \\
Pgi after & 0.49 & 0.79 & 0.59 & 0.90 \\
Pgm before & 0.00 & 0.05 & 0.22 & 0.49 \\
Pgm after & 0.01 & 0.08 & 0.01 & 0.12 \\
All loci before & 0.51 & 0.47 & 1.01 & 0.76 \\
All loci after & 0.49 & 0.46 & 0.81 & 0.65 \\
\hline
\end{tabular}

and after heat treatment at the Odh locus was zero, hence D was infinity. Some changes in genetic distance (D) before and after heat treatment were observed but these were small and non-significant, with large standard errors (Table 4). Thus there is no evidence to support the hypothesis that heat treatment results in a greater estimate of genetic divergence between the different forms of mussels.

\section{DISCUSSION}

Previous thermostability studies have typically described increased genetic variability at one or more allozyme loci when heat denaturing techniques have been employed (Bernstein et al. 1973, Singh et al. 1974, 1975, Milkman 1976, Bonhomme \& Selander 1978, Gosling 1979, Bernstein et al. 1980, Wilkins et al. 1980 , Okumura et al. 1981, Fujino et al. 1984, Okumura \& Fujino 1986). In some instances the increase in number 
of detectable alleles was very significant. For example, at 14 loci in 40 strains of the house mouse Mus musculus, Bonhomme \& Selander (1978) detected 27 allelic electromorphs and a further 20 allelic thermomorphs. In 10 species of the Drosophila virilis group, Singh et al. (1975) found that 3 apparently monomorphic loci were in fact polymorphic after heat treatment. We have found 3 polymorphic loci of the 8 mono- and polymorphic loci investigated to have thermosensitive alleles. The minimum increase in the total number of detectable alleles was $17 \%$ (Pgi at Bude), whilst the maximum was $100 \%$ (Pgm at Caswell). For all 3 loci and all 3 populations the mean increase in the total number of detectable alleles was $63 \%$. This is higher than the value quoted by Bonhomme \& Selander (1978) who estimated that heat denaturation detects an additional $50 \%$ of the variation that conventional electrophoresis detects.

Mytilus galloprovincialis is thought to have arisen allopatrically during the Pleistocene approximately 2 million years ago when the Mediterranean was cut off from the Atlantic by a drop in sea level (Barsotti \& Meluzzi 1968). When the Mediterranean and the Atlantic were rejoined at the end of the Pleistocene, $M$. galloprovincialis is presumed to have extended its range northwards. The biogeographic distribution of the 2 taxa is thus apparently a function of water temperature. $M$. edulis occurs where water temperature rarely exceeds $25^{\circ} \mathrm{C}$, whereas $M$. galloprovincialis occurs where water temperatures of $25^{\circ} \mathrm{C}$ occur for long periods (Seed 1976, Gosling 1984). Consequently, the 2 taxa are often classified as cold and warm-water forms. Mussels from the Mediterranean Sea therefore, arose in an environment where selection for heatresistance was greater than that experienced by mussels of the seas of the British Isles. Furthermore, $M$. galloprovincialis occurs at greatest frequency in the high shore (the area of greatest temperature-dependent selection) within sympatric populations of Ireland (Gosling \& Wilkins 1981) and hybrid populations of SW England (Skibinski 1983, Gardner \& Skibinski 1988). However, our results do not provide evidence in support of the hypothesis of a greater overall heat-sensitive allele frequency associated with $M$. edulis than with $M$. galloprovincialis. We did find a significantly greater heat-sensitive allele frequency associated with $M$. edulis, both in inter-population comparisons (Pgi locus, $M$. edulis vs $M$. galloprovincialis) and in the intrapopulation comparison (Odh locus, $M$. edulis vs $M$. galloprovincialis from the hybrid population). However, there was a greater frequency of the heat-sensitive $O d h^{10}$ allele in the $M$. galloprovincialis than in the $M$. edulis population. Thus, 2 significant results indicated that there was a greater heat-sensitive allele frequency in $M$. edulis, whilst one significant result indicated a greater heat-sensitive allele frequency in M. galloprovincialis. Of 36 Chi-square tests used to analyze differences between the 2 mussel types in the relative frequencies of heat-sensitive and heat-resistant forms of individual alleles and of all alleles at a single locus, 5 were significant and only 3 demonstrated significant differences solely between $M$. edulis-like and M. galloprovincialis-like mussels. Thus, overall our results provide no clear evidence of a significant difference in heat-sensitive allele frequencies between $M$. edulis and $M$. galloprovincialis, despite their presumed different evolutionary origins and present day ecological distributions.

When the Mytilus edulis and $M$. galloprovincialis of the allopatric populations, and the $M$. edulis and $M$. galloprovincialis of the sympatric population were compared using Nei's genetic distance (D) the amount of genetic divergence after heat treatment was similar to that observed before heat treatment. Thus, the data do not indicate any greater genetic divergence when the heat-sensitive alleles are considered. We examined a total of 8 loci ( 6 polymorphic and 2 monomorphic) and found heat-sensitive alleles at only 3 . This indicates a similar distribution of heat-sensitive alleles between the 2 mussel types although significant allele-by-allele and locus-by-locus differences were found. Skibinski et al. (1980) showed that genetic differences have evolved between $M$. edulis and $M$. galloprovincialis $(\mathrm{D}=0.172$ \pm 0.108 ) although these 2 forms cannot easily be assigned to subspecific rank. If the genetic divergence between $M$. edulis and $M$. galloprovincialis which occurred 1 to 2 million years ago (Skibinski et al. 1980) was caused by selection, then it did not result from selection primarily for heat-sensitive electromorphs because heat treatment has a non-significant effect upon the $D$ values. The same appears to be true of the selection against $M$. edulis in the high shore of hybrid populations in SW England. Thus, our results indicate that the basis of the selection against $M$. edulis-like individuals in SW England is unlikely to be allozyme heat-sensitivity.

The method of establishing allozyme thermosensitivity typically employs temperatures in the range of 50 to $60^{\circ} \mathrm{C}$ (e.g. Gosling 1979, Wilkins et al. 1980, Okumura et al. 1981, Fujino et al. 1984), temperatures which are far in excess of those naturally experienced by mussels. In common with the critical thermal maximal procedure often used by organismal biologists, thermostability measurements permit the rapid comparison of allozyme thermosensitivities. From an ecological point of view what is important and of considerable interest is the level of daily and annual temperature fluctuation, and perhaps more significantly, the thermal optimum for each allele. It is variation in allele-specific thermal optima within the range of environmentally encoun- 
tered temperatures which will determine individual fitness differences for allozyme heat tolerance, if they occur. To determine such differences it would be of value to investigate allozyme thermosensitivity at biologically relevant temperatures. For example, allozyme thermosensitivity differences between $M y$ tilus edulis and $M$. galloprovincialis might be assessed at $30^{\circ} \mathrm{C}$ for a period of perhaps 2 to $6 \mathrm{~h}$. Such a water temperature occurs in the Mediterranean (Biel 1944, Miller et al. 1970) but is approximately $10^{\circ} \mathrm{C}$ higher than the maximum water temperature experienced by mussels from SW England (Seed 1971, Bayne \& Widdows 1978, Hawkins et al. 1985).

Within 4 marine species, the ribbed mussel Geukensia demissa (Gosling 1979), the Pacific abalone Haliotis discus hannai (Wilkins et al. 1980, Okumura et al. 1981, Fujino et al. 1984), and in 2 species of algae Porphyra yezoensis and Undaria pinnatifida (Okumura \& Fujino 1986), a selective adaptational advantage to allozyme thermostability has been proposed because in all of these species intra-specific heat-resistant alleles occur with greater frequency in warmer regions. In our study there was no clear pattern of heat-sensitivity differences between the Mytilus edulis and M. galloprovincialis populations, and between the $M$. edulis and $M$. galloprovincialis of the hybrid population. Thus, in contrast to other studies our results provide no evidence of consistent thermostability differences in a situation where a priori such differences might have been expected.

Acknowledgements. The authors thank Mr Eric Roderick for help at the collecting sites. We thank an anonymous reviewer for helpful comments. This research was supported in part by a NERC Studentship to J.P.A.G.

\section{LITERATURE CITED}

Ahmad, M., Beardmore, J. A. (1976). Genetic evidence that the 'Padstow Mussel' is Mytilus galloprovincialis. Mar. Biol. 35: 139-147

Ahmad, M., Skibinski, D. O. F., Beardmore, J. A. (1977). An estimate of the genetic variation in the common mussel Mytilus edulis. Biochem. Genet. 15: 833-846

Anon. (1975). Weather in home waters. Vol. II. The waters around the British Isles and the Baltic. Part I. Meteorological Office, HMSO, London

Anon. (1976). Averages of temperature for the U.K., 1941-70. Meteorological Office, HMSO, London

Barsotti, G., Meluzzi, C. (1968). Osservazioni su Mytilus edulis L. e M. galloprovincialis Lmk. Conchiglie 4: 50-58

Bayne, B. L., Thompson, R. J., Widdows, J. (1976). Physiology I. In: Bayne, B. L. (ed.) Marine mussels. International biological programme 10. Cambridge University Press, Cambridge, p. 121-206

Bayne, B. L., Widdows, J. (1978). The physiological ecology of two populations of Mytilus edulis L. Oecologia 37: 137-162

Beaumont, A. R., Day, T. R., Gade, G. (1980). Genetic variation at the octopine dehydrogenase locus in the adductor muscle of Cerastoderma edule (L.) and six other bivalve species. Mar. Biol. Lett. 1: 137-148

Bernstein, S. C., Bowman, J. E., Noche, L. K. (1980). Genetic variation in Cameroon: thermostability variations of haemoglobin and of glucose-6-phosphodehydrogenase. Biochem. Genet. 18: 21-37

Bernstein, S. C., Throckmorton, L. H., Hubby, J. L. (1973). Still more genetic variability in natural populations. Proc. natn. Acad. Sci. U.S.A. 70: 3928-3931

Biel, E. R. (1944). Climatology of the Mediterranean area. Publication of the Institute of Meteorology of the University of Chicago, Illinois. Miscellaneous Reports No. 13

Bonhomme, F., Selander, R. K. (1978). Estimating total genetic variability in the house mouse. Biochem. Genet. 16: 287-297

Ceccherelli, V U., Barboni, A. (1983). Growth, survival and yield of Mytilus galloprovincialis Lamk, on fixed suspended culture in a Bay of the Po River delta. Aquaculture, Ansterdam 34: 101-114

Fujino, K., Sasaki, K., Okumura, S. (1984). Probable involvement of thermostability variations of enzymes in the mechanisms of occurrence of deficient abalone. Bull. Jap. Soc. scient. Fish. 50: 597-601

Gardner, J. P. A. (1989). Ecological and population genetics of hybrid mussels from south west England. Ph. D. thesis, University of Wales

Gardner, J. P. A., Skibinski, D. O. F. (1988). Historical and size-dependent genetic variation in hybrid mussel populations. Heredity, Lond. 61: 93-105

Gardner, J. P. A., Skibinski, D. O. F. (1990). Genotype-dependent fecundity and temporal variation of spawning in hybrid mussel populations. Mar. Biol. (in press)

Gosling, E. M. (1979). Hidden genetic variability in two populations of a marine mussel. Nature, Lond. 279: 713-715

Gosling, E. M. (1984). The systematic status of Mytilus galloprovincialis in western Europe; a review. Malacologia 25: $551-568$

Gosling, E. M., Wilkins, N. P. (1981). Ecological genetics of the mussels Mytilus edulis and $M$. galloprovincialis on Irish coasts. Mar. Ecol. Prog. Ser. 4: 221-227

Grant, W. S., Cherry. M. I. (1985). Mytilus galloprovincialis Lmk in southern Africa. J. exp. mar. Biol. Ecol. 90: 179-191

Harris, H. Hopkinson, D. A. (1977). Handbook of enzyme electrophoresis in human genetics. North Holland Publishing Co., Amsterdam

Hawkins, A. J. S., Salkeld, P. N., Bayne, B. L., Gnaiger, E., Lowe, D. M. (1985). Feeding and resource allocation in the mussel Mytilus edulis: evidence for time-averaged optimization. Mar. Ecol. Prog. Ser 20: 273-287

Milkman, R. (1976). Further evidence of thermostability variation within electrophoretic mobility classes of enzymes Biochem. Genet. 14: 383-387

Miller, A. R., Tchernia, P., Charnock, H., McGill, D. A. (1970). Mediterranean atlas of temperature, salinity, and oxygen profiles and data from cruises of R.V Atlantis and R.V Chain with the distribution of nutrient chemical processes. Woods Hole Oceanographic Institution, Woods Hole, Massachusetts

Nass, C. A. G. (1959). The $x^{2}$ test for small expectations in contingency tables with special reference to accidents and absenteeism. Biometrika 46:366-385

Nei, M. (1972). Genetic distance between populations. Am. Nat. 106: 283-292

Okumura, S., Fujino, K. (1986). Thermostability variations of enzymes in sea algae. Bull. Jap. Soc. scient. Fish. 52: 37-40

Okumura, S., Sasaki, K., Fujino, K. (1981). Thermostability 
variations at multiple loci in the Pacific abalone. Bull. Jap. Soc scient. Fish. 47: 1627-1630

Pugh, D. T (1987). Tides, surges and mean sea level. J. Wiley \& Sons, Chichester

Seed, R. (1971). A physiological and biochemical approach to the taxonomy of Mytilus edulis L. and Mytilus galloprovincialis Lmk from south-west England. Cah. Biol. mar 12: 291-322

Seed, R. (1976). Ecology. In: Bayne, B. L. (ed.) Marine mussels. International biological programme 10. Cambridge University Press, Cambridge, p. 13-66

Shaw, C. R., Prasad, R. (1970). Starch gel electrophoresis of enzymes - a compilation of recipes. Biochem. Genet. 4: $297-320$

Singh, R. S., Hubby, J. L., Lewontin, R. C. (1974). Molecular heterosis for heat-sensitive enzyme alleles. Proc. natn. Acad. Sci. U.S.A. 71: 1808-1810

Singh, R. S., Hubby, J. L., Throckmorton, L. H. (1975). A study of genic variation by electrophoretic and heat denaturing techniques at the Odh locus in members of the Drosophila virilis group. Genetics, Austin, Texas 80: 637-650

This article was submitted to the editor
Skibinski, D. O. F. (1983). Natural selection in hybrid mussel populations. In: Oxford, G. S., Rollinson, D. (eds.) Protein polymorphism: adaptive and taxonomic significance. Systematics Association Special Volume No.24. Academic Press, London, New York, p. 283-298

Skibinski, D. O. F., Beardmore, J. A. Cross, T. F. (1983) Aspects of the population genetics of Mytilus (Mytilidae: Mollusca) in the British Isles. Biol. J. Linn. Sac. 19: 137-183

Skibinski, D. O. F., Cross, T. F., Ahmad, M. (1980). Electrophoretic investigation of systematic relationships in the marine mussels Modiolus modiolus L., Mytilus edulis L., and Mytilus galloprovincialis Lmk. (Mytilidae; Mollusca). Biol. J. Linn. Soc. 13: 65-73

Trippa, G., Catamo, A., Lombardozzi, A., Cicchetti, R. (1978). A simple approach for discovering common nonelectrophoretic enzyme variability: a heat denaturation study in Drosophila melanogaster. Biochem. Genet. 16: 299-305

Wilkins, N. P., Fujino, K., Sasaki, K. (1980). Genetic studies on the Pacific abalone. IV. Thermostability difference among phosphoglucomutase variants. Bull. Jap. Soc. scient. Fish. 46: $549-553$

Manuscript first received: July 11, 1989

Revised version accepted: March 9, 1990 